\title{
Preface: Wind turbines: aeromechanics and farm optimization
}

\author{
Hui Hu${ }^{1} \cdot$ Xiaodong Wang ${ }^{2}$ \\ Published online: 25 April 2020 \\ (C) The Chinese Society of Theoretical and Applied Mechanics and Springer-Verlag GmbH Germany, part of Springer Nature 2020
}

\section{Preface}

With the oil and gas supply security and climate change emerging as high concerns, the need for renewable energy sources to alleviate dependence on hydrocarbons and reduce carbon dioxide $\left(\mathrm{CO}_{2}\right)$ emissions is becoming increasingly urgent. Wind energy is one of the cleanest renewable power sources in the world today. The U.S. Department of Energy (DOE) initiated the Wind Vision study where the costs and benefits of continued investments on wind energy was quantified. The study evaluated an ambitious, yet credible scenario in which wind energy will serve $20 \%$ of the nation's total electric power demand by 2030 , and $35 \%$ by 2050 . In Europe, the wind power generation accounted for $15 \%$ of all European electricity demand in the past year. Wind power installation in China has been growing by an annual rate of $\sim 10 \%$ in recent years. Currently, wind power has become the second largest renewable energy in China, only after hydro-power.

While more and more wind farms are being developed at the sites where wind energy source is plentiful, a good physical understanding about the development and separation of the boundary layer flows over the surfaces of wind turbine blades, the characteristics of the unsteady wake vortex structures behind wind turbines, and the resultant dynamic wind loads acting on the wind turbines is essential for the optimal design of the wind turbines. Wind turbine aeromechanics, micro-sitting, and array effects have been identified amongst the most significant research topics needed for wind resource characterization and wind power generation. This themed issue on "Wind turbines: Aeromechanics and farm optimization" consists of six research articles contributed by

Hui Hu

huhui@iastate.edu

Xiaodong Wang

wangxd@ncepu.edu.cn

1 Department of Aerospace Engineering, Iowa State University, Ames, IA 50011-1096, USA

2 Department of Energy, Power and Mechanical Engineering of North China Electric Power University, Beijing 102206, China the leading research groups in wind energy community to report the most updated research progress on wind turbine aeromechanics, separation flow control, and wind farm aerodynamics.

Attempts to extract more energy from the wind have led to bigger and bigger rotor diameters of wind turbine blades. While turbine rotor diameters of $\sim 120$ meters is quite common today, one of the major challenges faced by large-scale wind turbines is the constant variations in the direction and speed of the turbulent atmospheric boundary layer (ABL) winds which the turbines are exposed to. The ability of a wind turbine to respond to the rapid fluctuations of $\mathrm{ABL}$ winds in both speed and direction is hindered by the massive rotational inertia of the large-scale wind turbine assembly. As a result, wind turbine blades often operate under less than optimal conditions in relation to the instantaneous ABL wind speeds and directions. The highly turbulent nature of the ABL winds would induce unsteady wind loadings acting on the turbine blades, which has become a severe problem with larger rotor diameters. If the unsteady wind loads can be controlled properly and reduced to a lower level, it will lead to a lighter structure and longer fatigue lifetime of the turbine blades, thereby, better economics of wind power production. Mitigating the unsteady wind loads acting on a turbine blade could be realized by using various flow control methods. In this themed issue, Veerakumar et al. [1] presented an experimental study to utilize a dielectric-barrier-discharge (DBD) plasma actuation system to suppress massive flow separation over wind turbine blades to reduce the transient aerodynamic loadings acting on the turbine blades. A regression krigingbased metamodeling technique is employed to optimize the operation parameters of the DBD plasma system to suppress the massive flow separation/airfoil stall over the surface of a DU-96-W-180 turbine airfoil model. Zhang et al. [2] reported an experimental investigation to apply a leading-edge protuberance technology to control the fluctuations of the unsteady aerodynamic loads acting on a dynamically-pitching wind turbine airfoil. Wang et al. [3] presented a numerical study to use a leading-edge undulation control method to suppress 
the dynamic stall over the surface of a wind turbine airfoil model.

A modern wind farm usually consists of multiple wind turbines arranged in an organized pattern or array. The wake interferences among the upstream and downstream wind turbines have been found to affect the overall wind power production of the wind farm significantly. The wind turbines located in the near- and far-wake regions of upstream turbines in a typical wind farm would experience a significantly different surface wind field and wind loadings, in comparison to the ones located upwind due to the wake interference. Since a portion of the wind energy carried by the oncoming wind has already been harvested by the upstream turbines, significant velocity deficits would be generated in the wake flows behind the upstream turbines. As a result, downstream turbines see a considerably lower freestream velocity than the upstream turbines, and thus, less energy is available in the oncoming flows for the downstream turbines. It has been found that, by changing the yaw angle of the upstream turbine, i.e., operating the upstream turbine slightly outside its optimum settings, can significantly increase the power output of the downstream turbine. When the gain in the power output of the downstream turbine is greater than the loss in the power production from the yawed upstream turbine, the overall wind farm efficiency would be improved. In this themed issue, while Tafur et al. [4] reported their recent research work to improve an engineering model of three-dimensional rotation effects of the wind turbines, Ye et al. [5] proposed a multiple sliding method to simulate the aerodynamic characteristics of a typical horizontal-axis wind turbine under fixed and dynamic yawing operation. In addition, with the rapid development of offshore wind turbines in recent years, the method proposed by Ye et al. [5] can also be used to investigate the aerodynamic characteristics of offshore wind turbines with motions of floating platform.

Wind tunnel facilities have been widely used for wind turbine studies due to their capabilities to produce wellcontrolled flow environments. While a number of wind tunnel experiments have been performed in recent years to quantify turbine wake characteristics, majorities of the wind tunnel studies were conducted with homogeneous straight-line winds over a simplified flat surface. However, in reality, most of the wind turbines are sited in wind farms with complex terrains, which are neither flat nor with homogeneous straight-line winds. Although many important findings have been derived from the wind tunnel experiments, it is still highly desirable to obtain quantitative field measurement data to quantify the wake flow characteristics behind large-scale wind turbines operating in realistic atmospheric boundary layer (ABL) winds in order to gain further insight into the underlying physics for the optimal design of wind turbines, i.e., to improve the power productivity and fatigue lifetime of the wind turbines operating in onshore/offshore wind farms.
In this themed issue, Hong et al. [6] suggested a novel measurement method, named a super large scale particle image velocimetry (SLPIV) technique, to achieve quantitative flow field measurements to quantify the wake flow characteristic behind a $2.5 \mathrm{MW}$ utility-scale wind turbine operating in an onshore wind farm, where snow flakes were used as the tracer particles for the turbine wake flow measurements.

Another feature of this thematic issue is that we put an equal emphasis on both experimental and numerical studies to investigate wind turbine aeromechanics. Three papers contribute to experimental investigations. While Veerakumar et al. [1] and Zhang et al. [2] presented their experimental studies in wind tunnels to suppress the large-scale flow separation over a wind turbine airfoil model and to control unsteady aerodynamic loads acting on a dynamically pitching turbine blade model, Hong et al. [6] reported their research findings derived from a field experiment to quantify the wake flow characteristics behind a utility-scale wind turbine. The other three research papers devote to numerical simulations. Wang et al. [3] reported their numerical simulation results to examine the effects of undulation control on dynamic stall of a wind turbine airfoil/blade model. Ye et al. [5] presented a numerical study to quantify the unsteady aerodynamics characteristics of a horizontal wind turbine under yawed and dynamic yawing conditions. Tafur et al. [3] used a computational fluid dynamics (CFD) to calibrate a rotational augmentation model for wind turbine load simulation.

Finally, we appreciate the efforts made by all the contributors for this thematic issue. We are grateful to the Editor-in-Chief of Acta Mechanica Sinica (AMS), Prof. Wei Shyy, for inviting us as the guest editors of this thematic issue. We also thank the staff of the editorial office of AMS for managing, assistance, and support.

\section{References}

1. Veerkumar, R., Raul, V., Liu, Y., et al.: Metamodeling-based parametric optimization of DBD plasma actuation to suppress flow separation over a wind turbine airfoil model. Acta. Mech. Sin. 36(2), 260-274 (2020). https://doi.org/10.1007/s10409-020-00951-6

2. Zhang, Y.N., Zhang, M.M., Cai, C., et al.: Aerodynamic load control on a dynamically pitching wind turbine airfoil using leading-edge protuberance method. Acta. Mech. Sin. 36(2), 275-289 (2020). https://doi.org/10.1007/s10409-020-00939-2

3. Wang, B., Liu, J., Yang, Y.J., et al.: Numerical studies of undulation control on dynamic stall for reverse flows. Acta. Mech. Sin. 36(2), 290-306 (2020). https://doi.org/10.1007/s10409-020-00950-7

4. Tafur, B.S., Daniele, E., Stoevesandt, B., et al.: On the calibration of rotational augmentation models for wind turbine load estimation by means of CFD simulations. Acta. Mech. Sin. 36(2), 307-320 (2020). https://doi.org/10.1007/s10409-020-00949-0

5. Ye, Z.L., Wang, X.D., Chen, Z.W., et al.: Unsteady aerodynamic characteristics of a horizontal wind turbine under yawed and dynamic yawing. Acta. Mech. Sin. 36(2), 321-339 (2020). https:// doi.org/10.1007/s10409-020-00947-2 
6. Hong, J.R., Abraham, A.: Snow-powered research on utility-scale wind turbine flows. Acta. Mech. Sin. 36(2), 340-356 (2020). https:// doi.org/10.1007/s10409-020-00934-7

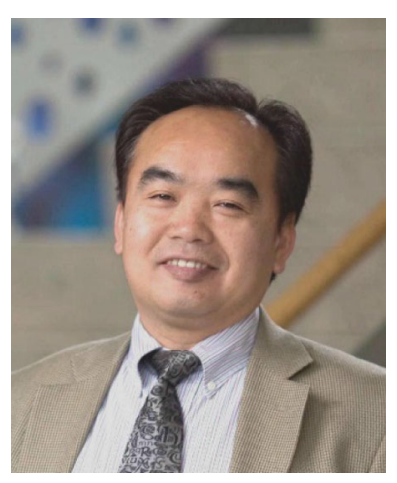

Dr. Hui Hu is the Martin C. Jischke Professor of Aerospace Engineering at Iowa State University. He received his $\mathrm{BS}$, $\mathrm{MS}$ and $\mathrm{PhD}$ degrees in Aerospace Engineering from Beijing University of Aeronautics and Astronautics (BUAA) in China, and a $\mathrm{PhD}$ degree in Mechanical Engineering from the University of Tokyo in Japan. His recent research interests include advanced flow diagnostics, aircraft icing physics and antiicing/de-icing technology, liquid fuel atomization and spray flow characterization, film cooling and thermal management of gas turbines, wind turbine aerodynamics and rotorcraft aeromechanics, micro-flows and micro-scale heat transfer in microfluidics. Dr. Hu is an ASME Fellow and AIAA Associate Fellow, and is serving as an editor of Experimental Thermal and Fluid Science-Elsevier and an associate editor of ASME Journal of Fluid Engineering. Dr. Hu received several prestigious awards in recent years, including 2006 NSF-CAREER Award, 2007 Best Paper in Fluid Mechanics Award (Measurement Science and Technology, IOP Publishing), 2009 AIAA Best Paper Award in Applied Aerodynamics, 2012 Mid-Career Achievement in Research Award of Iowa State University, 2013 AIAA Best Paper Award in Ground Testing Technology, and 2014 Renewable Energy Impact Award of Iowa Energy Center. Further information about Dr. Hu's technical background and recent research activities is available at: http://www.aere.iastate.edu/ huhui/.

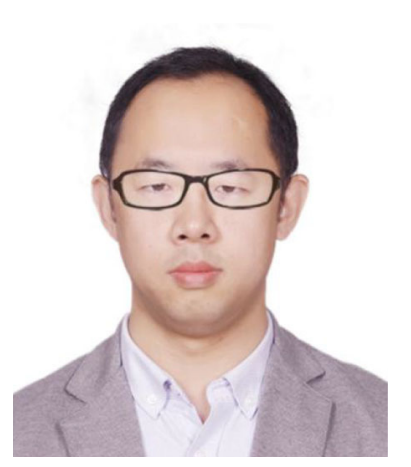

Dr. Xiaodong Wang is a Professor in the Department of Energy, Power and Mechanical Engineering of North China Electric Power University (NCEPU). He received his BS degree in Thermal Engineering from Harbin Engineering University (HEU), MS degree in Aerospace Engineering from China Aerospace Science Industry Corporation (CASIC), and $\mathrm{PhD}$ degree in Fluid Mechanics from Vrije Universiteit Brussel (VUB). $\mathrm{He}$ worked as a postdoctoral research fellow at the University of Toronto in Canada before he joined NCEPU. His research interests focus on the aerodynamics of wind turbine and development of numerical methods, including the unsteady numerical simulations of three dimensional flows around wind turbine rotors, aerodynamic design of wind turbine airfoils and blades, dynamic simulation and control method of offshore wind turbines, wake flows behind wind turbines and micro-sitting of wind farms. In numerical methods, he has been developing computational methods for large scale parallel computations of computational fluid dynamics (CFD), Uncertainty Quantification methods based on polynomial chaos, and validation and verification of CFD. 